\title{
The Association Between Femoral Artery Intima-Media Thickness and Serum Glucagon-Like Peptide-I Levels Among Newly Diagnosed Patients with Type 2 Diabetes Mellitus
}

This article was published in the following Dove Press journal: Diabetes, Metabolic Syndrome and Obesity: Targets and Therapy

Tuan Dinh Le, (iD) ${ }^{1 * *}$ Nga Phi Thi Nguyen, ${ }^{2,3 * *}$ Son Tien Nguyen, (iD) ${ }^{2,3}$ Hien Thi Nguyen, ${ }^{4}$ Hoa Thanh Thi Tran, (ID ${ }^{5}$ Thi Ho Lan Nguyen, ${ }^{6}$ Cuong Duy Nguyen, ${ }^{7}$ Giang Thi Nguyen, ${ }^{6}$ Xuan Thanh Nguyen, ${ }^{8}$ Bac Duy Nguyen, ${ }^{9}$ Son The Trinh, (ID) ${ }^{10}$ Tuan Anh Ngo, (DD 11 Binh Nhu Do, (D) ${ }^{12,13}$ Thuc Cong Luong (iD) ${ }^{8,14}$

'Department of Internal Medicine, Thai Binh University of Medicine and Pharmacy, Thai Binh, Vietnam; ${ }^{2}$ Department of Endocrinology, Military Hospital 103, Ha Noi, Vietnam; ${ }^{3}$ Department of Rheumatology and Endocrinology, Vietnam Military Medical University, $\mathrm{Ha} \mathrm{Noi}$,

Vietnam; ${ }^{4}$ Department of Physiology, Thai Binh university of Medicine and Pharmacy, Thai Binh, Vietnam; ${ }^{5}$ Department of Intensive Care Unit, National Hospital of Endocrinology, Ha Noi, Vietnam;

${ }^{6}$ Department of Internal Medicine, National Hospital of Endocrinology, Ha Noi, Vietnam; ${ }^{7}$ Department of Intensive Care Unit, Thai

Binh university of Medicine and Pharmacy,

Thai Binh, Vietnam; ${ }^{8}$ Department of Vascular Cardiology, Military Hospital 103, $\mathrm{Ha}$ Noi, Vietnam; ' ${ }^{\circ}$ epartment of Anatomy, Vietnam Military Medical University, $\mathrm{Ha} \mathrm{Noi}$,

Vietnam; ${ }^{10}$ Military Institute of

ClinicalEmbryology and Histology, Vietnam Military Medical University, Ha Noi,

Vietnam; " Department of Health

Economic, Vietnam Military Medical University, Ha Noi, Vietnam; ${ }^{12}$ Department of Infectious Disease, Vietnam Military Medical University, Ha Noi, Vietnam;

${ }^{13}$ Division of Military Science, Military

Hospital 103, Ha Noi, Vietnam; ${ }^{14}$ Director Office, Military Hospital 103, Ha Noi,

Vietnam

*These authors contributed equally to this work

Correspondence: Thuc Cong Luong; Son The Trinh

Email Icthuc@gmail.com;

trinhtheson@vmmu.edu.vn
Introduction: Endothelium dysfunction and decrease of incretin effects occur early in type 2 diabetes mellitus and these changes contribute to diabetic cardiovascular complications such as atherosclerosis, thick intima-media, coronary, and peripheral arterial diseases. In patients with diabetes, the femoral artery is a site of a high incidence of injury in peripheral vascular diseases, and atherosclerotic changes may appear earlier in the femoral artery compared to the carotid artery. This study was conducted to determine the prevalence of increased femoral artery intima-media thickness (IMT) and atherosclerotic plaque and their correlation with serum glucagon-like peptide-1 (GLP-1) levels in newly-diagnosed patients with type 2 diabetes mellitus.

Materials and Methods: A cross-sectional study was conducted on 332 patients with nT2D in the National Endocrinology Hospital, Vietnam from January 2015 to May 2018. IMT was measured by Doppler ultrasound and GLP-1 by enzyme-linked immunosorbent assay (ELISA). All data were analyzed with SPSS version 26 for Windows (SPSS Inc, Chicago, IL). Results: Prevalence of thick femoral artery IMT and atherosclerotic plaque was 38.2 and $22.3 \%$, respectively. There was a relationship between IMT and age, waist to hip ratio (WHR), systolic blood pressure (SBP), diastolic blood pressure (DBP), fasting GLP-1, high sensitive CRP (hsCRP) and 24-hour microalbuminuria secretion (24-h MAUS). The fasting serum GLP-1 (fGLP-1) levels were reduced significantly in patients with thickness and atherosclerosis femoral artery $(\mathrm{p}=0.001)$. After adjusting with other related factors, namely, DBP and estimated glomerular filtration rate (eGFR), whilst hsCRP and 24-h MAUS showed a significantly positive correlation to IMT (Standardized B and p of 0.242, 0.004 and 0.178, 0.043, respectively), fGLP-1 showed a significantly negative correlation to IMT (Standardized B $=-0.288, p=0.001$ ).

Conclusion: Among n2TD, the percentage for femoral artery thick IMT and atherosclerosis was $38.2 \%$ and $22.3 \%$ respectively, and serum GLP-1 was negatively correlated with thick IMT and atherosclerosis.

Keywords: newly diagnosed type 2 diabetes mellitus, intima-media thickness and atherosclerotic plaque, femoral artery, serum glucagon-like peptide-1 levels

\section{Introduction}

Type 2 diabetes mellitus which accounts for $90 \%$ of the total of diabetic patients causes severe complications and an economic burden. ${ }^{1}$ Albeit diabetes-induced arterial complications are not specific to type 2 diabetes mellitus, they occur at an early stage of the disease and their frequency is relatively high and remained the 
most prevalent cause of morbidity and mortality in diabetic patients. Pathologically, diabetes mellitus could lead to both micro- and macrovascular complications such as coronary artery disease, myocardial disease, hypertension, peripheral vascular disease, retinopathy, nephropathy and neuropathy. ${ }^{2}$ The prevalence of lower extremities artery disorders among other peripheral arterial disorders is quite high. ${ }^{3}$ Diabetes-induced lower extremities artery diseases could lead to limb amputation unless early diagnosis and plausible treatment. ${ }^{4}$ Common femoral arteries lay shallowly to the superficial surface and appear to be easy to evaluate morphology and size, recently, studies started focusing on the potential role of intima-media thickness measured at the femoral artery in assessing cardiovascular risk and increased IMT at the femoral arteries in a population suffering from hypertensive and diabetes patients. $^{5-7}$ Intima-media thickness under 2D ultrasound findings is one of the useful surrogate endpoints for arterial diseases and a feasible method in routine clinical practice. $^{8,9}$ Doppler ultrasonography is a practical method to discover and measure arterial media as well as sizes of atherosclerosis plaques, blood flow velocity, which results in a good screening apparatus to evaluate and to prognosis arterial thrombosis and occlusion with high accuracy.

Furthermore, the vascular system has characteristic changes in the course of diabetes. ${ }^{2}$ Diabetes could increase the risk of inflammation, platelet adhesion, and aggregation, coagulation disorders, and rheology. ${ }^{2}$ Additionally, recent studies also indicate that one of the early and characteristic features of the pathogenesis of type 2 diabetes is the loss of the incretin effect, which promotes the progression of vascular complications. ${ }^{10,11}$ Serum GLP-1 has been proved to have benefits in vascular systems, such as alleviating endothelium dysfunction, which is an early marker of atherosclerosis, develops as a result of arterial endothelial wall injury. ${ }^{12-14}$

The injuries to the arterial system in patients with type 2 diabetes occurs throughout the arterial system in the chronological order of the duration of the disease and varies with race. ${ }^{2}$ However, most recent studies have focused on patients with long-term diabetes and changes in the carotid artery, ${ }^{15-18}$ with less research on femoral changes as well as in newly diagnosed type 2 diabetes mellitus. ${ }^{15,19}$ Besides, the correlation between serum GLP1 and femoral artery abnormalities has not been elucidated. We executed this study to investigate the femoral arterial intima-media thickness prevalence and the correlation between serum GLP-1 levels and femoral artery intima-media thickness in nT2D, which helps us to get an insight into changes in the biology of type 2 diabetes mellitus.

\section{Materials and Methods Study Population and Design}

A cross-sectional study was conducted on 332 patients with nT2D in the National Endocrinology Hospital (Hanoi, Vietnam) from January 2015 to May 2018.

All patients were diagnosed with type 2 diabetes based on the American Diabetes Association guideline ${ }^{20}$ for the first time, which minimized other factors related to treatment therapy (such as acarbose, miglitol, metformin, insulin therapy $)^{21}$ to GLP-1 levels and to evaluate vascular injuries at the early stage of the disease. We excluded patients with types of diabetes other than type 2 diabetes mellitus, conditions which affected serum GLP-1 levels, ${ }^{21}$ severe chronic liver failure, heart failure or kidney failure, hemodynamic diseases (such as moderate-to-severe anemia, aplastic anemia, hemolytic anemia), systemic diseases (systemic lupus erythematosus, peripheral arterial occlusive diseases), infections (HIV, tuberculosis, foot ulcer, severe infections) and severe diabetic conditions (patients with hyperglycemic crises, such as hyperosmolarity and diabetic ketoacidosis, hypoglycemia). In addition, patients who were prescribed anticoagulant remedies were excluded from the study (sintrom, aspirin, clopidogrel, heparin).

All participants were provided with written informed consent and agreed to join our study; and the protocol was approved by the Ethical Review Committee of Vietnam Military Medical University, Vietnam (Reference No.168/ 2014/IRB-VMMU). The study was also conducted using good clinical practice following the Declaration of Helsinki of 1964, as revised in 2013.

\section{Clinical and Biochemical Assessments}

All patients were asked for their comorbidity diseases and history of drug usages. Anthropometric measurements and clinical examination were collected, namely history of smoking, age, gender, height, weight, WHR, blood pressure (at sitting positions), and pulse.

Patients were asked to fast from 22:00 and then blood samples were collected at 7:00 next morning. Lipid profiles (ie, total cholesterol, triglyceride, LDL-C, and HDL-C), AST, ALT, creatinine, electrolytes, protein, and hsCRP were measured by enzyme colorimetric method (Beckman AU680, 
USA). Serum insulin and C-peptide were quantified based on electrode chemiluminescence (COBAS E411, USA). HbA1c was measured in percentage by a high-performance liquid chromatography method (Adams A1C, Japan). Fasting plasma glucose (FPG) and two-hour postprandial glucose (2h-PPG) were measured by hexokinase methods (Beckman AU680, USA). Twenty-four-hour MAUS was measured by enzymatic turbidimeter autoanalyzer (Beckman AU680, USA). The whole blood cell was counted by K-4500, Japan.

\section{Bilateral Femoral Arteries Findings by Ultrasonography}

Patients were guided to lay on the supine position with flexible lower extremities. Under the standardized protocol for ultrasound in Vietnam, experienced ultrasound practitioners investigated femoral arteries from the inguinal ligament position downwardly to common femoral arteries to the bifurcation of the femoral artery into the subsartorial artery and the deep femoral artery by Philip HD 11 XE Color Doppler apparatus using a linear transducer (frequency of $7.5 \mathrm{MHz}$ ). Colored Doppler and continuous Doppler modes were employed to investigate the morphology and functions of arteries. We used the Pignoli method which was described elsewhere to measure intima-media thickness (IMT) of common femoral arteries in 2D mode. $^{22}$ The position for evaluating IMT $(\mathrm{mm})$ was at the distal walls of femoral arteries which were $2 \mathrm{~cm}$ from the bifurcation of the femoral artery into sub sartorial artery and deep femoral artery (supplementary picture S1 and $\underline{\mathrm{S}}$ ). The IMT was defined as the distance from the boundary of the vascular intima and lumen to the boundary of tunica media and tunica adventitia at end-diastole B-mode. IMT measurements were performed at both left and right femoral artery alternatively and the highest IMT was reported as an IMT variable for each patient, and then classified into 3 categories, namely normal IMT (less than $1 \mathrm{~mm})$, thick IMT $(1 \leq \mathrm{IMT}<1.5 \mathrm{~mm})$, and atherosclerosis (IMT $\geq 1.5 \mathrm{~mm}$ ) based on the classification for carotid artery. $^{23,24}$

\section{Assessment of Glucagon-Like Peptide-I Levels}

Patients at the time of their clinical visit were fasting at least 8 hours were aspirated blood for fasting serum GLP1 analysis (fGLP-1). All collecting tubes were added DPP4 inhibitor (DPP-IV Inhibitor, K579, Bio Vision, USA) before being added blood to prevent GLP-1 from the degradation by DPP4. Consequently, these blood samples were centrifuged at the velocity of 3000rpm for 15 minutes. Sera were then analyzed with commercially available kits (Human ELISA GLP-1 kits, IBL, Japan, $\# 27,784$ ) according to the manufacturer's protocol by ELISA apparatus (Thermo Fisher Scientific, USA). Changes in color were checked at a wavelength of $450 \mathrm{~nm}$. According to manufacture information, both of the intra-assay and inter-assay coefficients of variation were below $10 \%$.

\section{Statistical Analysis}

All continuous variables were expressed as mean \pm SEM or Median (interquartile range, Q1-Q3). Differences between groups were examined with either Student's $t$-test or Mann Whitney's test. Correlations between serum GLP-1 levels and other variables were evaluated with Pearson's and Spearman correlation analysis for normal distribution and skewed distribution variables, respectively. The chi-square test of association is used to discover if there is a relationship between two categorical variables, and Cramer's V value is employed to evaluate the strength of the association, if available. Kruskal-Wallis H-tests with Dunn's pairwise post hoc tests to analyze the differences in GLP-1 between groups of IMT. Multivariate linear regression was employed to analyze the effects of GLP-1 and other related factors and IMT, and VIF value < 10 was defined as no collinear for each variable in the multivariate regression. Two-tailed $P$-values $<0.05$ were set as statistically significant.

All data were analyzed with the SPSS version 26 (64bit edition) for Windows (SPSS Inc, Chicago, IL).

\section{Results \\ Demographic and Biomedical Findings}

A total of 332 patients with nT2D were enrolled in our study (for more details about demographic and biomedical findings, refer to Table 1). Fasting serum insulin levels, ALT, HDL-C, and platelet count at the time of diagnosing in women was higher than those in men. Male patients had higher serum triglyceride, creatinine, hsCRP, red blood cell counts, 24-h MAUS, eGFR, and IMT than those in women. There was no significant difference in both fGLP-1 levels between male and female patients. Surprisingly, regarding the characteristics of diabetes mellitus, albeit those patients were firstly diagnosed with type 2 diabetes mellitus, their glucose indices values (eg, FPG, 2hr-PPG, and HbAlc) 
Table I The Demographic and Biomedical Characteristics of the Study Population

\begin{tabular}{|c|c|c|c|}
\hline Variables, Unit & Men & Women & Overall \\
\hline Age, years & $51.91 \pm 0.79$ & $56.35 \pm 0.78$ & $54.01 \pm 0.57$ \\
\hline BMI, $\mathrm{kg} / \mathrm{m}^{2}$ & $22.58 \pm 0.21$ & $22.06(20.30-25.25)$ & $22.20(20.40-24.20)$ \\
\hline WHR & $0.92(0.88-0.94)^{\ddagger}$ & $0.89(0.86-0.93)^{\ddagger}$ & $0.91(0.87-0.94)$ \\
\hline SBP, mmHg & $124.00(\mid 20.00-140.00)$ & $120.00(120.00-140.00)$ & $120.00(120.00-140.00)$ \\
\hline DBP, mmHg & $80.00(70.00-80.00)$ & $80.00(70.00-80.00)$ & $80.00(70.00-80.00)$ \\
\hline $\mathrm{FPG}, \mathrm{mmol} / \mathrm{L}$ & $12.20(8.90-15.80)^{\dagger}$ & $10.30(7.90-14.20)^{\dagger}$ & $10.95(8.23-15.30)$ \\
\hline 2hr-PPG, mmol/L & $15.40(11.43-18.90)$ & I3.45 (II.05-18.38) & 14.60 (II.20-18.75) \\
\hline $\mathrm{HbAlc} \%$ & 10.10 (7.70-11.70) & $9.30(7.30-11.40)$ & $9.90(7.50-11.60)$ \\
\hline C-peptide, nmol/L & $0.69(0.46-I . I I)^{\dagger}$ & $0.83(0.59-1.20)^{\dagger}$ & $0.76(0.50-1.17)$ \\
\hline Insulin, pmol/L & $61.44(34.90-95.37)^{\dagger}$ & $78.4 \mid(48.94-I I 7.29)^{\dagger}$ & $68.32(41.31-105.77)$ \\
\hline Protein, g/L & $70.00(66.35-73.00)$ & $69.80(67.00-73.00)$ & $70.00(66.96-73.00)$ \\
\hline Triglycerides, $\mathrm{mmol} / \mathrm{L}$ & $2.45(1.56-4.27)^{\dagger}$ & $2.00(1.38-3.29)^{\dagger}$ & $2.22(\mathrm{I} .43-3.6 \mathrm{I})$ \\
\hline Total cholesterol, $\mathrm{mmol} / \mathrm{L}$ & $5.55 \pm 0.11$ & $5.41 \pm 0.11$ & $5.42(4.50-6.28)$ \\
\hline HDL-C, mmol/L & $1.17(0.99-1.43)^{\dagger}$ & $1.24(1.07-1.48)^{\dagger}$ & $1.19(1.03-1.45)$ \\
\hline LDL-C, mmol/L & $3.39(2.55-4.20)$ & $3.13 \pm 0.09$ & $3.14(2.45-4.13)$ \\
\hline $\mathrm{ALT}, \mathrm{U} / \mathrm{L}$ & $33.00(24.00-53.00)^{\dagger}$ & $30.00(22.00-44.00)^{\dagger}$ & $31.00(23.00-49.00)$ \\
\hline AST, U/L & $28.00(21.00-38.00)$ & $28.00(20.50-36.00)$ & $28.00(21.00-37.00)$ \\
\hline Creatinine, $\mu \mathrm{mol} / \mathrm{L}$ & $83.89 \pm 1.02^{\dagger}$ & $70.17 \pm 0.87^{\dagger}$ & $77.00(68.00-86.00)$ \\
\hline fGLP-I, pmol/L & $6.25(4.55-9.31)$ & $6.49(5.20-8.01)$ & $6.31(4.90-8.68)$ \\
\hline Calcium ion, $\mathrm{mmol} / \mathrm{L}$ & $1.20(1.17-1.24)$ & $1.19(1.17-1.23)$ & $1.20(1.17-1.23)$ \\
\hline hsCRP, mg/L & $2.21(1.10-5.30)$ & $2.11(1.05-4.86)$ & $2.17(1.09-5.18)$ \\
\hline Red blood cell, T/L & $5.14(4.69-5.42)^{\ddagger}$ & $4.79(4.58-5.00)^{\ddagger}$ & $4.94(4.62-5.26)$ \\
\hline Platelet, G/L & $238.50(203.50-282.00)^{\ddagger}$ & $271.56 \pm 4.40^{\ddagger}$ & $257.57 \pm 3.63$ \\
\hline 24-h MAUS, mg/L & II.50 (4.98-22.75) & $6.60(4.12-18.33)^{\dagger}$ & $8.90(4.49-21.58)$ \\
\hline eGFR, $\mathrm{mL} / \mathrm{min} / 1.73 \mathrm{~m}^{2}$ & $78.66(66.50-92.98)^{\ddagger}$ & $65.81(56.38-77.82)^{\ddagger}$ & $72.14(60.31-86.45)$ \\
\hline IMT, mm & $0.83(0.69-1.58)^{\dagger}$ & $0.77(0.65-1.43)^{\dagger}$ & $0.82(0.68-1.45)$ \\
\hline
\end{tabular}

Notes: Data were illustrated into Mean \pm SEM or Median (QI-Q3); ${ }^{\dagger} \mathrm{P}<0.05 ;{ }^{\ddagger} \mathrm{P}<0.00 \mathrm{I}$ (between male and female group).

Abbreviations: ALT, alanine transferase; AST, aspartate transferase; BMI, body mass index; DBP, diastolic blood pressure; eGFR, estimated glomerular filtration rate; FDG, fasting plasma glucose; fGLP-I, fasting serum glucagon-like peptide-I; HbAlc, hemoglobin Alc; HDL-C, high density lipoprotein cholesterol; hs-CRP, high sensitive C reactive protein; IMT, intima-media thickness; LDL-C, low density lipoprotein cholesterol; SBP, systolic blood pressure; WHR, waist-to-hip ratio; 24-h MAUS, 24-hour microalbuminuria secretion; 2hr-PPG, two-hour postprandial glucose.

were high (Table 1). Besides, the vast majority of the patients had normal BMI and there were no significant differences in BMI between male and female patients.

\section{Femoral Arteries Abnormalities in Newly Diagnosed Patients with Type 2 Diabetes Mellitus}

In our study, among 332 patients with T2D, thick IMT made up $38.2 \%$ and only $22.3 \%$ of patients suffered from femoral atherosclerosis.

There is a statistically significant association between gender and atherosclerosis (Cramer's V value of $13.0 \%$, $\mathrm{p}=0.018)$; age and both thick IMT and atherosclerosis (Cramer's V value of $41.0 \%, \mathrm{p}<0.001$ for the former and $35.2 \%, \mathrm{p}<0.001$ for the latter); hypertension and thick IMT (Cramer's V value of $22.1 \%, p<0.001$ ); high microalbuminuria and thick IMT and atherosclerosis (Cramer's V value of
$20.4 \%, p=0.003$ and $21.7 \%, p=0.002$, respectively); and eGFR and atherosclerosis (Cramer's V value of $13.8 \%, \mathrm{p}=$ 0.012). In particular, male patients and patients with poor glycemic control had a high percentage of atherosclerosis. Hypertension and high age at the time of diagnosis accounted for a high percentage of patients with both atherosclerosis and thick IMT. The highest rate of femoral abnormalities was seen in patients aged from 60 to 69 (Table 2).

\section{Serum Glucagon-Like Peptide-I Levels in Newly Diagnosed Patients with Type 2 Diabetes Mellitus and Correlation to Femoral Artery Abnormalities}

A Kruskal-Wallis H-tests showed that there was a statistically significant difference in GLP-1 level between the different IMT groups, $\chi^{2}(2)=15.113 ; \mathrm{p}=$ 0.001 (Table 3). Dunn's pairwise tests were carried out for 
Table 2 The Relationship Between Cardiovascular Risk Factors and Thick Intima-Media Thickness and Femoral Atherosclerosis

\begin{tabular}{|c|c|c|}
\hline Variables, Unit & $\begin{array}{l}\text { Thick IMT } \\
\text { n (\%) }\end{array}$ & $\begin{array}{l}\text { Atherosclerosis } \\
\text { n (\%) }\end{array}$ \\
\hline $\begin{array}{l}\text { Gender } \\
\qquad \begin{array}{l}\text { Male }(n=175) \\
\text { Female }(n=157) \\
\text { Overall }(n=332)\end{array}\end{array}$ & $\begin{array}{l}70(40.0) \\
57(36.3) \\
127(38.2)\end{array}$ & $\begin{array}{l}48(27.4)^{\dagger} \\
26(16.6)^{\dagger} \\
74(22.3)\end{array}$ \\
\hline $\begin{array}{l}\text { Age, years } \\
\qquad \begin{array}{l}<40(n=33) \\
40-49(n=74) \\
50-59(n=118) \\
60-69(n=93) \\
\geq 70(n=14)\end{array}\end{array}$ & $\begin{array}{l}2(6.0)^{\ddagger} \\
12(16.2)^{\ddagger} \\
37(31.4)^{\ddagger} \\
49(52.7)^{\ddagger} \\
10(71.4)^{\ddagger}\end{array}$ & $\begin{array}{l}\text { I }(3.0)^{\ddagger} \\
6(8.1)^{\ddagger} \\
24(20.3)^{\ddagger} \\
34(36.6)^{\ddagger} \\
9(64.2)^{\ddagger}\end{array}$ \\
\hline $\begin{array}{l}\text { Smoking } \\
\qquad \text { Active }(n=70) \\
\text { None }(n=262)\end{array}$ & $\begin{array}{l}26(37.1) \\
101(38.5)\end{array}$ & $\begin{array}{l}19(27.1) \\
55(21.0)\end{array}$ \\
\hline $\begin{array}{l}\text { Hypertension } \\
\text { Positive }(n=108) \\
\text { Negative }(n=224)\end{array}$ & $\begin{array}{l}58(53.7)^{\ddagger} \\
69(30.8)^{\ddagger}\end{array}$ & $\begin{array}{l}30(27.8) \\
44(19.6)\end{array}$ \\
\hline $\begin{array}{l}\text { BMI, } \mathrm{kg} / \mathrm{m}^{2} \\
\text { Malnutrition }(n=24) \\
\text { Normal }(n=167) \\
\text { Overweight }(n=81) \\
\text { Obesity }(n=60)\end{array}$ & $\begin{array}{l}6(25.0) \\
62(37.1) \\
33(40.7) \\
26(43.3)\end{array}$ & $\begin{array}{l}5(20.8) \\
38(22.8) \\
19(23.5) \\
12(20.0)\end{array}$ \\
\hline $\begin{array}{l}\text { Lipid disorders } \\
\text { Positive }(n=228) \\
\text { Negative }(n=79)\end{array}$ & $\begin{array}{l}88(38.5) \\
35(44.3)\end{array}$ & $\begin{array}{l}53(23.2) \\
17(21.5)\end{array}$ \\
\hline $\begin{array}{l}\text { Glucose control } \\
\text { Good-normal }(n=44) \\
\text { Poor }(n=288)\end{array}$ & $\begin{array}{l}\text { I6 (36.4) } \\
\text { III (38.5) }\end{array}$ & $\begin{array}{l}\text { II (25.0) } \\
63(21.9)\end{array}$ \\
\hline $\begin{array}{l}\text { 24-h microalbuminuria } \\
\quad \geq 30 \mathrm{mg} / \mathrm{l}(\mathrm{n}=32) \\
\quad<30 \mathrm{mg} / \mathrm{l}(\mathrm{n}=177)\end{array}$ & $\begin{array}{l}20(62.5)^{\dagger} \\
59(33.3)^{\dagger}\end{array}$ & $\begin{array}{l}14(43.7)^{\dagger} \\
35(19.8)^{\dagger}\end{array}$ \\
\hline $\begin{array}{l}\text { eGFR, } \mathrm{mL} / \mathrm{min} / 1.73 \mathrm{~m}^{2} \\
\qquad 60(\mathrm{n}=80) \\
\quad \geq 60(\mathrm{n}=252)\end{array}$ & $\begin{array}{l}38(47.5) \\
89(35.3)\end{array}$ & $\begin{array}{l}26(32.5)^{\dagger} \\
48(19.4)^{\dagger}\end{array}$ \\
\hline
\end{tabular}

Notes: ${ }^{\dagger} \mathrm{P}<0.05 ;{ }^{\ddagger} \mathrm{P}<0.001$

Abbreviations: BMI, body mass index; eGFR, estimated glomerular filtration rate; IMT, intima-media thickness.

the three pairs of groups (normal, thick IMT, and atherosclerosis). There was strong evidence ( $p<0.01$, adjusted using Bonferroni corrections) of a difference in GLP-1 between normal IMT and both thick IMT and atherosclerosis group in male patients and in overall $(\mathrm{p}<0.01)$. The median GLP-1 for normal IMT was $6.91 \mathrm{pmol} / \mathrm{L}$ compared to $4.73 \mathrm{pmol} / \mathrm{L}$ in thick IMT group and $5.52 \mathrm{pmol} / \mathrm{L}$ in atherosclerosis group in overall.
Table 3 The Relationship Between Fasting Glucagon-Like Peptide-I Levels and Intima-Media Thickness Stratified by Gender and Overall

\begin{tabular}{|c|c|c|c|}
\hline & $\begin{array}{l}\text { Normal } \\
\text { IMT }\end{array}$ & $\begin{array}{l}\text { Thick } \\
\text { IMT }\end{array}$ & Atherosclerosis \\
\hline \multicolumn{4}{|l|}{ Mean rank (n) } \\
\hline Male & $44.76(38)$ & $22.83(12)$ & $25.50(20)$ \\
\hline Female & $31.19(47)$ & $24.00(4)$ & $29.78(9)$ \\
\hline Overall & $74.68(85)$ & $42.69(16)$ & $5 \mathrm{I} .17(29)$ \\
\hline \multicolumn{4}{|l|}{ Median GLP-I (n) } \\
\hline Male* & $7.49(38)$ & $4.35(12)$ & $5.18(20)$ \\
\hline Female & $6.37(47)$ & $5.26(4)$ & $6.79(9)$ \\
\hline Overall* & $6.91(85)$ & $4.73(16)$ & $5.52(29)$ \\
\hline \multicolumn{4}{|l|}{ Test Statistics** } \\
\hline Male & \multicolumn{3}{|c|}{$\chi^{2}(2)=17.353 ; \mathrm{p}<0.00 \mathrm{I}, \mathrm{n}=70$} \\
\hline Female & \multicolumn{3}{|c|}{$\chi^{2}(2)=0.643 ; p=0.725, n=60$} \\
\hline Overall & \multicolumn{3}{|c|}{$\chi^{2}(2)=15.113 ; p=0.001, n=130$} \\
\hline
\end{tabular}

Notes: ${ }^{*} p<0.01$ between 3 groups by Dunn's pairwise test adjusted using Bonferroni corrections, **Kruskal-Wallis H-tests

Abbreviations: IMT, intima-media thickness; GLP-I, glucagon-like peptide - I.

In the univariate linear regression analysis, fGLP-1, age, WHR, systolic blood pressure (SBP), diastolic blood pressure (DBP), total cholesterol, hsCRP and 24-h MAUS illustrated the significant correlation to IMT. After adjusting with other related factors (namely, DBP and eGFR), whilst hsCRP and 24-h MAUS showed a significantly positive correlation to IMT, fGLP-1 showed a significantly negative correlation to IMT (Table 4).

\section{Discussion}

\section{The Prevalence of Abnormal Femoral Arterial Intima-Media Thickness and Cardiovascular Risk Factors}

The endothelium has been considered as an endocrine organ that regulates and maintains hemodynamic functions of the vessel wall. ${ }^{25,26}$ Since intima-media was directly exposed to blood flow, as a consequence, the early and first injury was seen in intima-media. Functional changes of endothelium play a pivotal role in the pathogenesis of both micro- and macrovascular complications in diabetes, amongst, chronic hyperglycemia contributes greatly to IMT changes. ${ }^{2}$ In our research, the percentage of patients with thick femoral arterial IMT was $38.2 \%$ and patients with femoral arterial atherosclerosis made up $22.3 \%$, which was in line with the previous study. ${ }^{19}$ The prevalence of femoral atherosclerosis increases greatly among patients with 
Table 4 Univariate and Multivariate Linear Regression Analysis: Standardized Beta Coefficients of Independent Variables and Femoral Intimal Media Thickness

\begin{tabular}{|c|c|c|c|c|c|}
\hline \multirow[t]{2}{*}{ Determinants, Unit } & \multicolumn{2}{|c|}{ Univariate } & \multicolumn{3}{|l|}{ Multivariate } \\
\hline & $\mathbf{r}$ & P-value & Standardized B & P-value & VIF \\
\hline Age, years** & 0.440 & 0.000 & & & \\
\hline $\mathrm{BMI}, \mathrm{kg} / \mathrm{m}^{2}$ & 0.081 & 0.140 & & & \\
\hline WHR** & 0.171 & 0.002 & & & \\
\hline $\mathrm{SBP}, \mathrm{mmHg} \mathrm{g}^{* *}$ & 0.303 & 0.000 & & & \\
\hline DBP, mmHg & 0.167 & 0.002 & 0.027 & 0.750 & 1.087 \\
\hline fGLP-I, pmol/L & -0.433 & 0.000 & -0.288 & 0.001 & 1.092 \\
\hline FPG, mmol/L & 0.036 & 0.515 & & & \\
\hline Triglyceride, $\mathrm{mmol} / \mathrm{L}$ & -0.003 & 0.952 & & & \\
\hline Total cholesterol, $\mathrm{mmol} / \mathrm{L}$ & 0.061 & 0.266 & & & \\
\hline $\mathrm{HDL}-\mathrm{C}, \mathrm{mmol} / \mathrm{L}$ & -0.006 & 0.912 & & & \\
\hline LDL-C, mmol/L & 0.057 & 0.315 & & & \\
\hline hsCRP, mg/L & 0.211 & 0.000 & 0.242 & 0.004 & 1.027 \\
\hline 24-h MAUS, mg/L & 0.167 & 0.015 & 0.178 & 0.043 & 1.133 \\
\hline eGFR, $\mathrm{mL} / \mathrm{min} / 1.73 \mathrm{~m}^{2}$ & -0.163 & 0.003 & -0.150 & 0.074 & 1.035 \\
\hline
\end{tabular}

Notes: P-value in Italic was significant. **These variables were excluded from multivariate regression model due to their intercorrelations and correlations with other variables.

Abbreviations: BMI, body mass index; DBP, diastolic blood pressure; eGFR, estimated glomerular filtration rate; fGLP-I, fasting serum glucagon-like peptide-I; FPG, fasting plasma glucose; HDL-C, high density lipoprotein cholesterol; hsCRP, high sensitive C reactive protein; LDL-C, low density lipoprotein cholesterol; SBP, systolic blood pressure; VIF, variance inflantion factor; WHR, waist-to-hip ratio; 24-h MAUS, 24-hour microalbuminuria secretion.

poor control of glucose in comparison to those with good-normal glycemic control. Type 2 diabetes mellitus leads to macrovascular and microvascular complications which occurred early and it is a major and known risk factor for atherosclerosis development. One of the mechanisms was the reduction of endothelial NO function due to the reduction in synthesizing and the increase in degradation, ${ }^{27}$ insulin resistance, ${ }^{28}$ lowgrade systemic inflammation. ${ }^{29}$ As aortic-IMT is also increased by $22.8 \%$ in adult diabetes mellitus patients. ${ }^{30}$ There is a clear relationship between the thickness of the intima-media complex in the common carotid artery and the prevalence of plaque in the carotid and femoral arteries. This demonstrates that the increase in IMT in both the general carotid and femoral arteries contributes to the reflection of atherosclerosis of the arterial system, but interestingly, the changes in the artery wall may occur earlier in the femoral than in the carotid artery. ${ }^{5}$ Thick IMT has been proven as one cue for early atherosclerosis. Regarding femoral atherosclerosis, its role in the prognosis of emboli of other organs of the human body such as the brain and the heart has been not elucidated, however, early changes of femoral IMT among patients with type 2 diabetes mellitus were seen commonly at the early stage of diabetes, which suggests the role of femoral IMT screening in the follow-up of diabetic vascular complications.

In our study, in patients with higher age, the percentage of thick IMT and plaque were higher than those in younger patients, and patients aged from 60 to 69 showed the highest percentage of thick IMT and plaque, which was in line with the previous study. ${ }^{19}$ Belcaro et al followed up the progress of arterial plaque for 6 years concluded that measuring IMT could be a surrogate for the progress of endothelial dysfunctions related to ages. ${ }^{31}$ Factors associated with cardiovascular events in type 2 diabetics such as age, SBP, and HbAlc as well as diabetes onset were positively correlated with carotid IMT, in contrast, the hemoglobin concentration was inversely correlated with the carotid IMT. The most significant correlation was between the time of onset of diabetes, HbAlc, and hemoglobin and carotid IMT after correction for other risk factors. ${ }^{30}$

Besides, our results also outlined that there was a relation between IMT and gender (ie, the prevalence of thick IMT and atherosclerosis appeared to be higher in male patients than in female ones). Depairon et al (2010) measured femoral intima-media thickness in 98 healthy participants aged from 20 to 60 without any atherosclerosis risk factors and found that mean IMT was 0.543 and 
$0.562 \mathrm{~mm}$ in female and male people, respectively. The increased level of IMT was $0.0012 \mathrm{~mm} /$ year in females and $0.0031 \mathrm{~mm} /$ year in males. Besides, they outlined that IMT depended on age and gender. ${ }^{32}$

In patients with $\mathrm{T} 2 \mathrm{D}$ with hypertension, the percentage of thick IMT and atherosclerosis was significantly higher than those in patients without hypertension, which suggested the synergic effect of hypertension and T2D worsened femoral artery abnormalities. Our result was consistent with other studies. $^{23,33,34}$ While hypertension remains an important risk factor for the development of generalized atherosclerosis, it has also been implicated as a major risk factor in cardiovascular disease. Hypertension has been shown to be one of the main causes of thickening and hardening of arterial walls through complex mechanisms including an increase in smooth muscle mass, connective tissue deposition, endothelial dysfunction, and abnormal production of endotheliumderived relaxing factors. ${ }^{35}$ In Nigerians with hypertension, carotid and femoral thickness increased significantly compared to healthy subjects and the thick femoral IMT was one of the pinpoints of atherosclerosis. ${ }^{36}$

Our results showed that the percentage of femoral atherosclerosis was significantly higher in patients with high 24-h MAUS and low eGFR when compared with those with normal eGFR and negative 24-h MAUS. Theoretically, microalbuminuria and chronic kidney diseases are the risks of cardiovascular disease and contributed to the abnormal changes of endothelial function. ${ }^{37,38}$ In patients with chronic kidney disease, the femoral IMT was significantly higher than that in the healthy group with $p=0.004$. Vascular atherosclerotic levels were associated with femoral IMT in both chronic kidney disease and healthy subjects $(\mathrm{p}<0.001$ and $\mathrm{p}=0.009$, respectively). Additionally, the femoral IMT above $0.57 \mathrm{~mm}$ served as a predictor of pathological progression to atherosclerosis with a high sensitivity of $92 \%$. ${ }^{39}$

Albeit some studies outlined that lipid profile, especially LDL-C and HDL-C, related to the thickness of carotid arteries, ${ }^{40,41}$ some studies found a moderate correlation between them. ${ }^{42,43}$ In our study, we did not find out this correlation after adjustment for other factors.

\section{The Relation Between Femoral Arterial Intima-Media Thickness and Fasting Serum Glucagon-Like Peptide-I}

Our study also outlined the correlation between serum GLP-1 levels and IMT by femoral arterial Doppler ultrasound performance in 130 patients. A Kruskal-Wallis
H-tests showed that there was a statistically significant difference in GLP-1 level between the different IMT groups; GLP-1 decreased significantly in patients with thick IMT and atherosclerosis in male patients in overall. Endothelial dysfunctions (ie, arterial motor dysfunctions, procoagulant factors, and proinflammation cytokines) played a pivotal role in the progression of diabetic microvascular complications in patients with type 2 diabetes mellitus. Previous research has proved that serum GLP-1 levels made a great contribution to not only prevent the arterial wall from inflammatory response, atherosclerosis, oxidative stress, but also increase endothelium relaxations. Serum GLP-1 benefits endothelial functions via numerous mechanisms. Nagashima et al (2011) found that GLP-1 inhibits the formation of foam macrophages via cAMP and hence prevents the inflammatory response to the artery which closely related to negative feedback of CD36 and ACAT-1. GLP-1 affected macrophages population and modulated adherence molecular, such as IL-10, CD136, and CD204. By activation of STAT3 via the GLP-1-receptor dependent manner, GLP-1 reduced pro-inflammatory response and macrophage accumulation along the arterial wall. $^{44}$ Katja Piotrowski et al (2013) noted that GLP-1 was correlated to coronary arterial abnormalities in human (which was diagnosed via coronary angiography) via multivariate logistic regression including age, gender, BMI, hypertension, diabetes, smoking, triglyceride, HDL-C, hsCRP and glomerular filtration rate $(\mathrm{OR}=2.53,95 \% \mathrm{CI}$ : 1.12-6.08, $\mathrm{p}=0.03) .^{45}$ Antonio Ceriello et al (2013) found that GLP-1 reduced endothelial dysfunction, inflammatory response in patients with type 2 diabetes mellitus with or without hypo- or hyperglycemic attack via the effect to nitro tyrosine, 8-iso prostaglandin F2 $\alpha$, sICAM-1, and interleukin-6. ${ }^{12}$ Moreover, both GLP-1 and dipeptidyl peptidase IV inhibitors upregulate endothelial NO synthetase and improve NO production in adjunction with reduction of cyclooxygenase expression that increases endothelium relaxations. ${ }^{13}$ In the univariate linear regression analysis, fGLP-1, age, WHR, SBP, DBP, total cholesterol, hsCRP, and 24-h MAUS illustrated the significant correlation to IMT. Due to many factors that could affect the thickness of the femoral arterial wall, ${ }^{41}$ after adjusting with other related factors (namely, DBP and eGFR), whilst hsCRP and 24-h MAUS illustrated a significantly positive correlation to IMT, fGLP-1 showed a significantly negative correlation to IMT. Although our results did not reveal the correlation between BMI, lipid profiles, and arterial thickness, there would be some reasons. First, our median 
BMI of the patients was not too high, which was one of the characteristics of Asian patients with type 2 diabetes mellitus ${ }^{46,47}$ so the number of overweight or obese patients was not enough. Second, other lipid profiles marker such as triglycerides is not directly atherogenic. ${ }^{48}$

There would be some limitations to our research. Our study was just an observational study and we did not measure the thickness of femoral arteries wall in the control group. Moreover, we did not check the reproducibility of ultrasonography practitioners.

\section{Conclusion}

In conclusion, it is evident that this study has shown among patients with type 2 diabetes mellitus, diabetesinduced vascular complications have progressed for a long time, which have been proved with the percentage for femoral artery thick IMT and atherosclerosis were 38.2 and 22.3 respectively, and the high incidence of femoral artery abnormalities was seen in older patients. Moreover, serum GLP-1 levels reduced significantly in patients with thickness and atherosclerosis femoral artery, and GLP-1 negatively correlated with IMT.

\section{Abbreviations}

ALT, alanine transferase; AST, aspartate transferase; BMI, body mass index; DBP, diastolic blood pressure; eGFR, estimated glomerular filtration rate; FDG, fasting plasma glucose; fGLP-1, fasting serum glucagon-like peptide-1; HbA1c, hemoglobin A1c; HDL-C, high-Density lipoprotein cholesterol; hs-CRP, high sensitive $\mathrm{C}$ reactive protein; IMT, intima-media thickness; LDL-C, low-density lipoprotein cholesterol; SBP, systolic blood pressure; WHR, waist-to-hip ratio; 24-h MAUS, 24-hour microalbuminuria secretion; 2hr-PPG, two-hour postprandial glucose.

\section{Ethical Statement}

All participants were provided with written informed consent and agreed to join our study; and the protocol was approved by the Ethical Review Committee of Vietnam Military Medical University (Reference No.168/2014/ IRB-VMMU). The study was also conducted using good clinical practice following the Declaration of Helsinki of 1964, as revised in 2013.

\section{Acknowledgments}

We thank all the staff in the Outpatients Department of the National Hospital of Endocrinology, Vietnam for supporting the study.

\section{Author Contributions}

All authors made a significant contribution to the work reported, whether that is in the conception, study design, execution, acquisition of data, analysis, and interpretation, or in all these areas; took part in drafting, revising or critically reviewing the article; gave final approval of the version to be published; have agreed on the journal to which the article has been submitted; and agree to be accountable for all aspects of the work.

\section{Funding}

There was no financial support for the research, and publication of this article.

\section{Disclosure}

The authors declare that they have no conflicts of interest for this work.

\section{References}

1. Saeedi P, Petersohn I, Salpea P, et al. Global and regional diabetes prevalence estimates for 2019 and projections for 2030 and 2045: results from the international diabetes federation diabetes Atlas, 9th edition. Diab Res Clin Pract. 2019;157:107843. doi:10.1016/j. diabres.2019.107843

2. Clark N. Peripheral arterial disease in people with diabetes. Diab Care. 2003;26(12):3333-3341. doi:10.2337/diacare.26.12.3333

3. Nativel M, Potier L, Alexandre L, et al. Lower extremity arterial disease in patients with diabetes: a contemporary narrative review. Cardiovasc Diabetol. 2018;17:138. doi:10.1186/s12933-018-0781-1

4. Shatnawi NJ, Al-Zoubi NA, Hawamdeh HM, Khader YS, Garaibeh K, Heis HA. Predictors of major lower limb amputation in type 2 diabetic patients referred for hospital care with diabetic foot syndrome. Diab, Metab Syndr Obes Targets Ther. 2018;11:313-319. doi:doi:10.2147/ DMSO.S165967

5. Wendelhag I, Wiklund O, Wikstrand J. Atherosclerotic changes in the femoral and carotid arteries in familial hypercholesterolemia. Ultrasonographic assessment of intima-media thickness and plaque occurrence. Arterioscler Thromb a J Vasc Biol. 1993;13(10): 1404-1411. doi:10.1161/01.ATV.13.10.1404

6. Temelkova-Kurktschiev T, Koehler C, Henkel E, Hanefeld M. Leukocyte count and fibrinogen are associated with carotid and femoral intima-media thickness in a risk population for diabetes. Cardiovasc Res. 2002;56(2):277-283. doi:10.1016/S0008-6363(02)00 547-3

7. Jeremiás Z, Makó K, Bogdan A, Miu I, Șerdean A, Benedek T. Femoral intima-media thickness, risk factors, and markers of inflammation in cardiovascular disease. J Interdiscip Med. 2018;3 (3):141-151. doi:10.2478/jim-2018-0032

8. Giannoukas AD, Antoniou GA, Saleptsis V, Baros C, Griffin M, Nicolaides AN. Common femoral artery intima-media thickness as marker for cardiovascular disease in asymptomatic adults. Vasa J Vasc Dis. 2009;38(2):147-154. doi:10.1024/0301-1526.38.2.147

9. Kirhmajer MV, Banfić L, Vojković M, Strozzi M, Bulum J, Miovski Z. Correlation of femoral intima-media thickness and the severity of coronary artery disease. Angiology. 2011;62(2):134-139. doi:10.1177/ 0003319710375087 
10. Seino Y, Yabe D. Glucose-dependent insulinotropic polypeptide and glucagon-like peptide-1: incretin actions beyond the pancreas. J Diab Investig. 2013;4(2):108-130. doi:10.1111/jdi.12065

11. Holst JJ, Knop FK, Vilsbøll T, Krarup T, Madsbad S. Loss of incretin effect is a specific, important, and early characteristic of type 2 diabetes. Diab Care. 2011;34(S2):S251S257. doi:10.2337/dc11-s227

12. Ceriello A, Novials A, Ortega E, et al. Glucagon-like peptide 1 reduces endothelial dysfunction, inflammation, and oxidative stress induced by both hyperglycemia and hypoglycemia in type 1 diabetes. Diab Care. 2013;36:2346-2350. doi:10.2337/dc12-2469

13. Liu L, Liu J, Huang Y. Protective effects of glucagon-like peptide 1 on endothelial function in hypertension. J Cardiovasc Pharmacol. 2015;65(5):399-405. doi:10.1097/FJC.0000000000000176

14. Sheikh A. Direct cardiovascular effects of glucagon like peptide-1. Diabetol Metab Syndr. 2013;5(47):1-13. doi:10.1186/1758-5996-5-47

15. Ho HC, Chen MF, Hwang JJ, Lee YT, Su TC. Intima-media thickness of lower-limb arteries associated with fasting and post-challenge plasma glucose levels. J Atheroscler Thromb. 2009;16(6):748-755. doi: $10.5551 /$ jat.836

16. Mitsuhashi N, Onuma T, Kubo S, Takayanagi N, Honda M, Kawamori R. Coronary artery disease and carotid artery intima-media thickness in Japanese type 2 diabetic patients. Diab Care. 2002;25:1308-1312. doi:10.2337/diacare.25.8.1308

17. Folsom AR, Eckfeldt JH, Weitzman S, et al. Relation of carotid artery wall thickness to diabetes mellitus, fasting glucose and insulin, body size, and physical activity. Atherosclerosis Risk in Communities (ARIC) study investigators. Stroke. 1994;25:66-73. doi:10.1161/01.str.25.1.66

18. Wagenknecht LE, D'Agostino RB, Haffner SM, Savage PJ, Rewers M. Impaired glucose tolerance, type 2 diabetes, and carotid wall thickness: the Insulin Resistance Atherosclerosis Study. Diab Care. 1998;21:1812-1818. doi:10.2337/diacare.21.11.1812

19. Ms A. Thickened common femoral artery intima media thickness: a surrogate marker for subclinical peripheral arterial disease in patients with type 2 diabetes mellitus. Egypt $J$ Geriatr Gerontol. 2017;4(1):11-14. doi:10.21608/ejgg.2017.5347

20. Johnson EL, Feldman H, Butts A, et al. Standards of medical care in diabetes 2019 abridged for primary care providers. Clin Diabetes. 2019. doi:10.2337/cd18-0105

21. Wang X, Liu H, Chen J, Li Y, Qu S. Multiple factors related to the secretion of glucagon-like peptide-1. Int J Endocrinol. 2015;1-11. doi:10.1155/2015/651757

22. Pignoli P, Tremoli E, Poli A, Oreste P, Paoletti R. Intimal plus medial thickness of the arterial wall: A direct measurement with ultrasound imaging. Circulation. 1986;74(6):1399-1406. doi:10.1161/01.CIR 74.6.1399

23. Soneye M, Adekanmi A, Obajimi M, Aje A. Intima-media thickness of femoral arteries and carotids among an adult hypertensive Nigerian population: a case-control study to assess their use as surrogate markers of atherosclerosis. Ann Afr Med. 2019;18(3):158-166. doi:10.4103/aam.aam_57_18

24. Godoi ETAM, Brandt CT, Lacerda HR, et al. Intima-media thickness in the carotid and femoral arteries for detection of arteriosclerosis in human immunodeficiency virus-positive individuals. Arq Bras Cardiol. 2017;108(1):3-11. doi:10.5935/abc.20160197

25. Deanfield JE, Halcox JP, Rabelink TJ. Endothelial function and dysfunction: testing and clinical relevance. Circulation. 2007;115:1285-1295. doi:10.1161/CIRCULATIONAHA.106.652859

26. Inagami T, Naruse M, Hoover R. Endothelium as an Endocrine Organ. Annu Rev Physiol. 1995;57:171-189. doi:10.1146/annurev. ph.57.030195.001131

27. Aljada A, Dandona P. Effect of insulin on human aortic endothelial nitric oxide synthase. Metabolism. 2000;49(2):147-150. doi:10.1016/ S0026-0495(00)91039-4

28. Muniyappa R, Iantorno M, Quon MJ. An integrated view of insulin resistance and endothelial dysfunction. Endocrinol Metab Clin North Am. 2008;37(3):685-711. doi:10.1016/j.ecl.2008.06.001
29. Tripathy D, Mohanty P, Dhindsa S, et al. Elevation of free fatty acids induces inflammation and impairs vascular reactivity in healthy subjects. Diabetes. 2003;52(12):2882-2887. doi:10.2337/diabetes.52.12.2882

30. Koc AS, Sumbul HE. Increased aortic intima-media thickness may be used to detect macrovascular complications in adult type II diabetes mellitus patients. Cardiovasc Ultrasound. 2018;16:8. doi:10.1186/ s12947-018-0127-x

31. Belcaro G, Nicolaides AN, Laurora G, et al. Ultrasound morphology classification of the arterial wall and cardiovascular events in a 6-year follow-up study. Arterioscler Thromb Vasc Biol. 1996;16:851-856. doi:10.1161/01.ATV.16.7.851

32. Depairon M, Darioli R, Romanens M. Cardiovascular risk prediction with ultrasound. Cardiovasc Med. 2010;13(09):255-264. doi:10.4414/ cvm.2010.01523

33. Zanchetti A, Bond MG, Hennig M, et al. Risk factors associated with alterations in carotid intima-media thickness in hypertension: baseline data from the european lacidipine study on atherosclerosis. J Hypertens. 1998;16:946-961. doi:10.1097/00004872-199816070-00008

34. Lemne C, Jogestrand T, De Faire U. Carotid intima-media thickness and plaque in borderline hypertension. Stroke. 1995;26:34-39. doi:10.1161/01.STR.26.1.34

35. Kaul S, Alladi S, Mridula R, et al. Prevalence and risk factors of carotid intima-media thickness in asymptomatic individual subjects in a tertiary care center in India. Ann Indian Acad Neurol. 2015;18 (4):430-444. doi:10.4103/0972-2327.165481

36. Ayoola OO, Bolarinwa RA, Onakpoya UU, Adedeji TA, Onwuka CC, Idowu BM. Intima-media thickness of the common femoral artery as a marker of leg ulceration in sickle cell disease patients. Blood Adv. 2018;2(22):3112-3117. doi:10.1182/ bloodadvances.2018023267

37. Malyszko J. Mechanism of endothelial dysfunction in chronic kidney disease. Clin Chim Acta. 2010;411(1920):1412-1420. doi:10.1016/j. cca.2010.06.019

38. Stam F, van Guldener C, Schalkwijk CG, Ter Wee PM, Donker AJM, Stehouwer CDA. Impaired renal function is associated with markers of endothelial dysfunction and increased inflammatory activity. Nephrol Dial Transplant. 2003;18(5):892-898. doi:10.1093/ndt/ gfg080

39. Nezami N, Ghabili K, Shokouhi-Gogani B, et al. The relationship between carotid and femoral artery intima-media thickness and histopathologic grade of atherosclerosis in patients with chronic kidney disease. Nephron. 2018;139(2):159-169. doi:10.1159/000487491

40. Yang C, Sun Z, Li Y, Ai J, Sun Q, Tian Y. The correlation between serum lipid profile with carotid intima-media thickness and plaque. BMC Cardiovasc Disord. 2014;14:181. doi:10.1186/1471-2261-14181

41. Qu B, Qu T. Causes of changes in carotid intima-media thickness: a literature review. Cardiovasc Ultrasound. 2015;13:46. doi:10.1186/ s12947-015-0041-4

42. Idigo FU, Ayogu EN, Onwuzu SWI, Anakwue AMC, Nwogu UB, Anakwue RC. Correlating carotid intima-media thickness with lipid profile: does it improve sonographic diagnosis of subclinical atherosclerosis? J Diagnostic Med Sonogr. 2019;35(6):453-458. doi: $10.1177 / 8756479319867617$

43. Wiinberg N, Lebech AM, Kristoffersen US, et al. P.089 carotid intima-media thickness in non-smoking hiv patients treated with antiretroviral therapy: focus on lipid profile. Artery Res. 2006;1 (S1):S48S48. doi:10.1016/s1872-9312(07)70112-6

44. Shiraishi D, Fujiwara Y, Komohara Y, Mizuta H, Takeya M. Glucagon-like peptide-1 (GLP-1) induces M2 polarization of human macrophages via STAT3 activation. Biochem Biophys Res Commun. 2012;425(2):304-308. doi:10.1016/j.bbrc.2012.07.086

45. Piotrowski K, Becker M, Zugwurst J, et al. Circulating concentrations of GLP-1 are associated with coronary atherosclerosis in humans. Cardiovasc Diabetol. 2013;12(117):1-7. doi:10.1186/14752840-12-117 
46. Gujral UP, Pradeepa R, Weber MB, Narayan KMV, Mohan V. Type 2 diabetes in South Asians: similarities and differences with white Caucasian and other populations. Ann N Y Acad Sci. 2013; 1281:51-63. doi:10.1111/j.1749-6632.2012.06838.x

47. Cho YS, Lee J-Y, Park KS, Nho CW. Genetics of type 2 diabetes in east asian populations. Curr Diab Rep. 2012;12(6):686-696. doi:10. 1007/s11892-012-0326-Z
48. Talayero BG, Sacks FM. The role of triglycerides in atherosclerosis. Curr Cardiol Rep. 2011;13:544. doi:10.1007/s11886-011-0220-3

\section{Publish your work in this journal}

Diabetes, Metabolic Syndrome and Obesity: Targets and Therapy is an international, peer-reviewed open-access journal committed to the rapid publication of the latest laboratory and clinical findings in the fields of diabetes, metabolic syndrome and obesity research. Original research, review, case reports, hypothesis formation, expert opinion and commentaries are all considered for publication. The manuscript management system is completely online and includes a very quick and fair peer-review system, which is all easy to use. Visit http://www.dovepress.com/testimonials.php to read real quotes from published authors. 